\title{
Mengenal Jenis-Jenis Insulin Terbaru untuk Pengobatan Diabetes
}

\author{
Hafshah Nurul Afifah \\ PT. Cendo Pharmac eutic al Industries, Bandung, Jawa Barat, Indonesia \\ Terbit online : 30 Oktober 2016
}

\section{Abstrak :}

Jumlah penderita diabetes di dunia semakin meningkat, khususnya pada kondisi Diabetes Tipe 2 ketika pankreas semakin sulit menghasilkan insulin dalam jumlah yang memadai untuk mengatasi resistensi insulin, pasien membutuhkan suplementas insulin. Tipe insulin bervariasi bergantung pada seberapa cepat insulin bekerja, waktu kerja maksimal, dan durasi kerja insulin dalam tubuh. Di artikel ini dijelaskan jenis-jenis insulin terbaru secara ringkas beserta contohnya yang tersedia di Indonesia.

Keyword: insulin, diabetes

\section{Pendahuluan}

Jumlah penderita Diabetes di dunia semakin meningkat, khususnya pada kondisi Diabetes Tipe 2 ketika pankreas semakin sulit menghasilkan insulin dalam jumlah yang memadai untuk mengatasi resistensi insulin, pasien membutuhkan suplementasi insulin. Lalu bagaimana perkembangan sediaan insulin hingga kni? tenaga kesehatan khususnya apoteker wajib mengetahuinya.

\section{Apa itu Insulin?}

Insulin merupakan hormon yang terbentuk secara alami dan diproduksi oleh pankreas. Insuin dibutuhkan untuk mengangkut gula dari darah ke dalam sel-sel tubuh yang kemudian digunakan untuk menghasilkan energi.

Gejala-gejala yang dihasilkan akibat kadar gula tinggi (hiperglikemia) di antaranya kadar gula tinggi dalam urin, sering buang air kecil, dan sering merasa haus, sedangkan gejala kadar gula rendah (hipoglikemia) di antaranya tubuh bergetar, gugup dan resah, keringat dingin, mudah marah, kebingungan, detak jantung cepat, kepala terasa pusing atau melayang, lapar dan haus, mengantuk, pandangan buram atau terganggu, kebas pada bibir atau lidah, nyeri kepala, lemas dan kelelahan, mimpi buruk, kejang, dan hilang kesadaran.

\section{Tipe Diabetes}

Diabetes tipe 1 (DT1) merupakan suatu kondisi kronik saat pankreas menghasilkan sedikit insulin atau tidak dapat menghasilkan insulin. Menurut American Diabetes Association, hanya 5\% dari pasien diabetes yang mengalami bentuk diabetes ini. 
Penderita diabetes paling banyak mengalami diabetes tipe 2 (DT2). Faktor-faktor risiko diabetes ini di antaranya:

- Kelebihan beratbadan dan obesitas

- Kurangnya aktivitas fisik

- Riwayatkeluarga

- Genetik

- Ras dan etnis

- Usia

- Tekanan darah tinggi

- Kadar kolesterol abnormal

Penderita DT2 dapat menghasilkan insulin, tetapi tubuhnya tidak dapat merespons dengan baik; kondisi ini dikenal sebagai resistensi insulin. Pengobatan DT2 biasanya dimulai dengan perubahan pola makan dan gaya hidup serta obat-obatan oral. Saat pankreas semakin sulit menghasilkan insulin dalam jumlah yang memadai untuk mengatasi resistensi insulin, pasien membutuhkan suplementasi insulin.

\section{Terapi insulin}

Terapi insulin harus bersifat individual dan diseimbangkan dengan asupan makanan dan olahraga. Saat pasien mulai menggunakan insulin untuk mengatas diabetes, dosis awal hanyalah titik awal. Seirng waktu, kebutuhan insulin dipengaruhi oleh faktor-faktor seperti kenaikan atau penurunan berat badan, perubahan kebiasaan makan, dan penambahan obat obatan lainnya. Kebutuhan insulin sering kali meningkat dan dosis harus diatur ulang untuk dapat memenuhi kebutuhan kadar insulin baru.

Insulin diinjeksikan secara subkutan (di bawah kulit). Lokasi injeksi umumnya di perut, bokong, paha, dan lengan atas. Dengan menggilir lokasi injeksi, pasien dapat menghindari lipohipertropi, yaitu peningkatan pertumbuhan atau ukuran sel-sel lemak di bawah kulit. Ketika terjadi lipohipertropi, area di bawah kulit pada lokasi injeksi menjadi berlemak. Karena itu, untuk memperoleh laju absorpsi yang baik dan untuk menghindari perubahan pada kulit lokasi injeksi, penting untuk menggilir lokasi injeksi insulin.

\section{Jenis-Jenis Insulin}

Tipe insulin bervariasi bergantung pada seberapa cepat insulin bekerja, waktu kerja maksimal, dan durasi kerja insulin dalam tubuh. Karena terapi insulin selalu membutuhkan peningkatan dosis dan tidak nyaman, banyak dokter merekomendasikan penggunaan insulin basal dengan insulin yang diberikan pada waktu makan saat dibutuhkan. insulin basal ditujukan untuk menjaga kadar glukosa darah tetap terkendali selama periode puasa atau tidur.

Terdapat dua jenis insulin basal, yaitu insulin intermediate-acting (kerja sedang) dan insulin longacting (kerja-panjang). Untuk menyerupai mekanisme tubuh pasien sehat dalam melepaskan insulin, insulin bolus (insulin short-acting (kerja singkat) atau rapid-acting (kerja-cepat)) harus diberikan untuk mencegah peningkatan kadar glukosa darah setelah makan.

\section{Insulin reguler atau short-acting:}

- Digunakan pada waktu makan

- Mulai bekerja dalam waktu 30 menit

- Bekerja maksimal dalam 2 hingga 3 jam

- Efek bertahan hingga 6 jam 
- Insulin Neutral Protamine Hagedom (NPH) harus di-resuspensi (mengaduknya perlahan dengan memutar pen) sebelum digunakan

- Contoh : Humulin R; Novolin R; dan, untuk pompa insulin, Velosulin, hanya Humulin R yang tersedia di Indonesia

Insulin kerja-cepat:

- Digunakan pada waktu makan

- Mulai bekerja dalam 15 menit

- Bekerja maksimal dalam sekitar 1 jam

- Efeknya bertahan hingga 4 jam

- Contoh : glulisine, lispro, dan aspart, semua produk belum tersedia di Indonesia

Insulin kerja-sedang:

- Digunakan sehari sekali

- Bekerja maksimal 4 hingga 8 jam setelah injeksi

- Efeknya bertahan hingga 18 jam

- Jika diinjeksikan sebelum tidur, insulin akan bekerja maksimal pada dini hari, yaitu saat insulin paling dibutuhkan

- Contoh : NPH, Humulin N, dan Novolin N, hanya Humulin N tersedia di Indonesia

Insulin kerja-panjang :

- Menurunkan kadar glukosa secara bertahap

- Efeknya dapatbertahan hingga 24 jam

- Contoh : detemir (Levemir) dan glargine (Lantus), tersedia di Indonesia

- Ultralong-acting insulin :

- Digunakan sehari sekali

- Efeknya dapatbertahan lebih dari 24 jam

- Contoh : degludec (Tresiba), belum tersedia di Indonesia

Premixed insulin memiliki kombinasi insulin kerja-sedang dan kerja-cepat dalam jumlah yang spesifik dalam 1 botol atau pen insulin. Produk ini, seperti Humulin 70/30, Novolin 70/30, Novolog 70/30, Humulin 50/50, dan Humalog Mix 75/25, umumnya digunakan 2 atau 3 kali sehari sebelum waktu makan.

\section{Kekuatan Insulin dan Spuit}

Insulin tersedia dalam beberapa kekuatan, meskipun sebagian besar insulin dibuat dalam kekuatan $\mathrm{U} 100$, artinya terdapat 100 unit insulin dalam setiap $\mathrm{mL}$ cairan.

Terdapat 3 ukuran spuit insulin U100, yaitu 1/3 cc (dapat menampung 30 unit insulin), 1/2 $\propto$ (menampung 50 unit insulin), dan $1 \mathrm{cc}$ (menampung 100 unit insulin). Jenis spuit yang digunakan bergantung seberapa banyak insulin yang dibutuhkan.

Beberapa insulin baru dengan konsentrasi lebih besar dari U100 baru-baru ini beredar di pasaran. Produk ini dikembangkan untuk pasien yang membutuhkan dosis insulin yang besar untuk mengurangi volume injeksi dan frekuensi injeksi. Toujeo (insulin glargine [rDNA origin]), suatu insulin basal kerja panjang yang digunakan sehari sekali, mengandung $300 \mathrm{unit} / \mathrm{mL}$ (U300). Untuk pasien dengan resistensi insulin parah yang membutuhkan lebih dari 200 unit per hari, insulin dengan konsentrasi tinggi (U500) tersedia di pasaran. 


\section{Sistem Penghantaran Insulin}

Terdapat beragam sistem penghantaran insulin, di antaranya dengan menggunakan spuit, pen insulin (sekali pakai atau isi ulang), injektor tanpa jarum yang menggunakan tekanan sangat tinggi untuk mendorong semprotan halus insulin melalui kulit, dan insulin hirup. Pompa insulin menghantarkan insulin yang dibutuhkan tubuh 24 jam sehari melalui kateter yang dipasang di bawah kulit. Meskipun perangkat ini telah digunakan untuk menangani DT1 selama 35 tahun, penggunaannya semakn luas dalam 15 tahun terakhir.

Semua insulin NPH, serta lente dan ultralente (insulin kabut (all cloudy insulins)), perlu dikocok untuk memastikan suspensi insulin merata di seluruh cairan. Untuk memastikan keefektifannya dan untuk mengurangi fluktuasi glukosa darah, pastikan agar insulin tercampur secara merata dengan membolakbalikkan botol dari ujung ke ujung selama beberapa kali, atau dengan memutar botol perlahan di antara telapak tangan.

\section{Penyimpanan Insulin}

Insulin yang utuh masih dalam kemasan harus disimpan di lemari es sampai pada saatnya digunakan dan dapat digunakan hingga tanggal kedaluwarsa yang tertera pada label. Jangan pernah menyimpan insulin di dalam lemari beku (freezer) dan insulin tidak boleh terpapar panas atau sinar matahari langsung. Setelah dibuka, vial insulin dapat disimpan pada suhu ruangan.

Insulin dalam suhu ruangan tidak akan terlalu menyebabkan rasa sakit saat diinjeksikan. Umumnya, sebagian besar vial insulin baik digunakan selama 28 hari. Pen sekali pakai harus disimpan pada suhu ruangan setelah digunakan dan baik digunakan selama 10, 14, 28, atau 42 hari, bergantung jenis insulin. Periksa kembali sisipan/brosur obat dan ikuti petunjuknya.

Insulin bukan merupakan obat penyembuh diabetes. Akan tetapi jika digunakan dengan tepat disertai asupan makanan dan aktivitas fisik yang sesuai, insulin dapat membantu mengendalikan diabetes dan mengurangi risiko komplikasi.

\section{Referensi:}

1. Beth Bolt.The ABCs of Insulin. www.pharmacytimes.com/publications/issue/2016/October2016/TheABCs-of-Insulin. (Diakses 30 Oktober 2016)

2. Diabetes basics. American Diabetes Association website. www.diabetes.org.(Diakses 30 Oktober 2016)

3. Diabetes treatment: using insulin to manage blood sugar. Mayo Clinic website. www.mayoclinic.org/diseases-conditions/diabetes/in-depth/diabetes-treatment/art20044084.(Diakses 30 Oktober 2016)

Artikel ini terbit online di http://farmasetika.com/2016/10/30/mengenal-jenis-jenis-insulin-terbaruuntuk-pengobatan-diabetes/ 